\title{
rant \\ COVID-19 Vaccination and Mental Disorders, What Has Been Accomplished and Future Direction
}

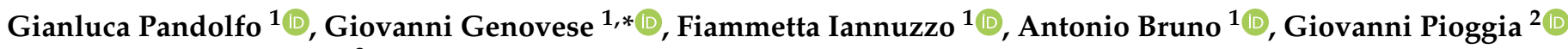 \\ and Sebastiano Gangemi ${ }^{3}$
}

Citation: Pandolfo, G.; Genovese, G.; Iannuzzo, F.; Bruno, A.; Pioggia, G.; Gangemi, S. COVID-19 Vaccination and Mental Disorders, What Has Been Accomplished and Future Direction. Brain Sci. 2022, 12, 292. https://doi.org/10.3390/brainsci 12020292

Academic Editor: Rosemary Sheehan

Received: 22 December 2021

Accepted: 18 February 2022

Published: 20 February 2022

Publisher's Note: MDPI stays neutral with regard to jurisdictional claims in published maps and institutional affiliations.

Copyright: (c) 2022 by the authors. Licensee MDPI, Basel, Switzerland. This article is an open access article distributed under the terms and conditions of the Creative Commons Attribution (CC BY) license (https:// creativecommons.org/licenses/by/ $4.0 /)$.
1 Department of Biomedical and Dental Sciences, Morphological and Functional Images, University of Messina, 98121 Messina, Italy; gpandolfo@unime.it (G.P.); f.iannuzzo@libero.it (F.I.); antonio.bruno@unime.it (A.B.)

2 Institute for Biomedical Research and Innovation, National Research Council of Italy (IRIB-CNR), 98125 Messina, Italy; giovanni.pioggia@cnr.it

3 School and Operative Unit of Allergy and Clinical Immunology, Department of Clinical and Experimental Medicine, University of Messina, 98125 Messina, Italy; gangemis@unime.it

* Correspondence: giovannigeno@live.it

\begin{abstract}
The consequences of the pandemic on mental health are among the most important side effects of COVID-19. Wide concerns have emerged both regarding vaccine hesitation in the general population, and the vaccine's implementation plan. The aim of this study is to evaluate how the scientific community has investigated the relationship between the COVID-19 vaccine and mental disorders. Contrary to expectations, having a full-blown psychiatric pathology seems to positively affect the attitude towards the vaccine, except for PTSD. The intense fear that accompanied the current world emergency has made this pandemic unique; we discuss how it might be one of the factors involved in this result. Further experimental investigations are needed to estimate how personality traits, hyperarousal, and negative emotions influence vaccine compliance both in the general population and in people living with mental disorders.
\end{abstract}

Keywords: COVID-19 vaccination; mental disorders; psychiatry; vaccine hesitancy

\section{Introduction}

The prompt development of an anti-coronavirus disease 2019 (COVID-19) vaccine has aroused opposite reactions in the general population with harsh debate between those who favored its use and those who did not, even before its development was completed. The use of social media might have contributed to misinformation [1] rather than emphasizing how this achievement is the culmination of a research path whose foundations can be traced back to 1990 [2], combined with the contemporary effort of dozens of laboratories in the world at a time of crisis. The first two COVID-19 vaccines put at the disposal of health care systems use lipid nanoparticles to deliver antigen mRNA into human cells to induce protein expression. The complexity of the mechanism of action compared to traditional vaccines, the latter closest to an understandable and ancient principle such as similia similibus curantur, led non-experts to look with suspicion at these new technologies, or even at conspiracy theories regarding mass genome editing, highlighting how the pandemic reveals some fundamental conflicts of our time, for instance between ethics and technique.

In this context, concerns regarding both vaccine hesitation in the general population and vaccine implementation have emerged. One of the categories considered to be vulnerable are people with serious mental disorders (SMI), which prevalence is estimated to be between $0.4 \%$ and $7.7 \%$ [3]. The consequences of the pandemic on mental health are among the most important side effects of COVID-19 [4]. According to a survey by the World Health Organization evaluating the impact of COVID-19 on mental, neurological, and substance use services, the majority of mental health services reported disruptions of essential interventions. In order to respond to decreased volumes both in inpatient and 
outpatient settings, high income countries have replaced in-person consultations by using telemedicine or helplines [5]. Despite the effort, current research highlights that people with mental disorders are at increased risk of COVID-19 infection and mortality [6-8], and the worsening of a diagnosed psychiatric illness [9-11], including during adolescence [12]. Furthermore, the expression of psychiatric symptoms in the general population has increased during the COVID-19 pandemic [13-15], which might correspond with pandemic trends [13]. In fact, as well as a trigger factor due to the psychological burden of the emergency, the pandemic could represent an opportunity for the emergence of subthreshold mental disorders that were silent within structured daily activities [16].

\section{Aims}

The relationship between COVID-19 vaccination and mental disorders is an important emergent field of study. Although several articles have focused on the neuro-psychiatric implications of the pandemic $[17,18]$, few have investigated the attitudes of people with mental illness towards vaccination. Mazereel et al. [19] did not find articles about this issue at the time of their review and state that research on this topic is urgently needed. Given the novelty of this research topic, the aim of the current study is to report an overview of the articles examining COVID-19 vaccination in relation to mental disorders, and discuss how scientific research has addressed this topic, in order to provide suggestions for further research and direction. We also believe that the current study can help identify useful insights for the management of future pandemic emergencies.

\section{Attitudes toward Vaccination and Mental Disorders, Studies before COVID-19}

Numerous studies have investigated vaccine acceptance or hesitancy in the general population as complex phenomena [20]. Vaccine safety was identified as the largest area of concern [20]. Vaccine acceptance entails trust in the vaccine, the provider, and in the policymaker, which includes the health system and government [21]. On the other hand, vaccine hesitancy, defined as the delay in acceptance of vaccination despite availability, is associated to confidence, complacency, convenience [22], and socioeconomic determinants [23].

A few studies have investigated psychiatric factors: State anxiety was found to be higher in healthcare workers who evaluate influenza A/H1N1 vaccination as unsafe [24]; Chan et al. found a positive correlation between the anxiety level and the vaccine uptake willingness in Hong Kong's general population [25]. Moreover, anxious-depressive symptoms were associated with vaccine uptake in pregnant women [26].

According to our knowledge, the first study to explore vaccination among patients diagnosed with mental illness was the study from Lorenz et al. [27]: they observed from 2010 to 2011 a lower rate $(28.4 \%)$ of vaccination against flu in psychiatric patients compared to the general population. Significant factors associated with the vaccination status were perceived effectiveness, recommendations from healthcare providers, and perception that they can acquire the flu from the vaccine. These results were similar to an interesting systematic review from Schmid et. al. [28] which evaluated evidence about influenza vaccine hesitancy from 2005 to 2016. They proposed a model that takes into account physical, context, and sociodemographic determinants which interact with psychological determinants. Among the psychological factors, the most important appeared to be utility, risk perception, and social benefit, while considerable contextual barriers were access to vaccination, interaction with healthcare system, and reception of a direct recommendation from medical personnel or relatives. Moreover, barriers for seasonal and pandemic influenza uptake were very similar in their study. Maguire et al. [29] investigated the will to adopt protective behaviors in 71 patients with schizophrenia compared to the general population during the influenza pandemic in 2009. Patients with schizophrenia were generally willing to receive vaccination (74\%) but significantly less compared with control group $(80.1 \%)$. Wearing a face mask was the least precautionary measure likely to be adhered to for both groups and it was perceived as minimally effective. In the schizophrenia group, self-efficacy and perceived risk from swine flu were positive predictors of willingness both to wear a face mask and to receive 
vaccination. The same research group [30] showed that fear was a robust predictor for willingness to adopt all protective measures except for isolation in schizophrenia patients and a weak predictor in the control group. On the other hand, anxiety was associated with a reduced perceived risk in SCZ groups. A recent study from Lawrence et al. based on an elderly sample found that having a mental health diagnosis was associated with greater odds of flu vaccine receipt [31].

\section{Expert Opinion during COVID-19 Pandemic}

We can identify two main phases in research on COVID-19 vaccination and mental disorders: the first phase includes studies before vaccine distribution when the expected lack of vaccines doses made researchers focus mainly on whether to prioritize vaccination for patients with severe mental illness and identify operational guidelines to facilitate the access to care; the second phase includes experimental studies on vaccination and psychopathological variables.

During the first phase the consensus view of researchers was that people with serious mental illness [32-38] or specific psychiatric disorders (substance use disorders [39-42], psychosis [43]) needed vaccination priority as others with severe diseases did. The same opinion was stated by the most important psychiatric association, the American Psychiatric Association (APA), which released a COVID-19 guidance manuscript "the role of the psychiatrist in the equitable distribution of the COVID-19 vaccine" [44]. The majority of these research papers were expert opinions based on evidence both from previous data and on data from the current COVID-19 pandemic.

Two manuscripts stated a more controversial position about COVID-19 vaccination in severe psychiatric patients [45,46]. The manuscript from Rehman et al. (2021) [45] was conceptualized at the early stage of pandemic emergency, and highlighted the psychiatric side-effects of medication and possible onset of anxiety, depression, fear, frustration, delusions, hallucination, and anorexia nervosa, based on data on exposure to previous vaccines, while highlighting the importance of psychological intervention. Yang et al. [46] declared the need to be cautious regarding vaccine implementation in high-risk subpopulations such as patients with SMI, given the controversial long term efficacy and safety. This point was well discussed by Toubasi et al. [47], who conducted a meta-analysis based on data from 634,338 COVID-19 patients (10.7\% of them were diagnosed with mental disorders). This study showed an increased risk of COVID-19 severity and mortality in this sample; these results leading the authors to recommend vaccination.

Therefore, consistent with the scientific data available at that time, the widespread concern was to not be able to reach this type of patients, with consequences both for people with psychiatric conditions and for the general population. Palermo et al. (2020) [48] in their perspective article highlighted the need for a comprehensive evaluation of physical and psychological profile to improve adherence in frailty patients. One paper [49] focused on the serious difficulties related to the vaccination of people with SMI in a specific geographic area (Latin America). Researchers also developed a plan of action to facilitate vaccination in people with mental illness $[39,50]$. Interestingly, both studies highlighted the key role of vaccine recommendation from healthcare providers, together with peer support and educational programs, and they suggested providing vaccination within mental health services. Moreover, Salles et al. [51] hypothesized that comorbid insomnia and sleep apnea is a risk factor for reduced response to the COVID-19 vaccination.

\section{Original Research}

During the COVID-19 pandemic, vaccine administration experimental articles that evaluated vaccine adherence/hesitancy in people with mental disorders emerged. The results are reported for major topics and summarized in chronological order in Table 1. 
Table 1. Selected manuscripts evaluating psychiatric factors and COVID-19 vaccination.

\begin{tabular}{|c|c|c|c|}
\hline Reference & Study Design & Assessment & Main Findings \\
\hline [52] & Cohort study & $\begin{array}{c}\text { Structured } \\
\text { online surveys }\end{array}$ & $\begin{array}{c}\text { Vaccine hesitancy does not appear to be a major barrier for } \\
\text { vaccine uptake amongst patients with mental illness in Denmark. }\end{array}$ \\
\hline [53] & $\begin{array}{c}\text { Cross } \\
\text { sectional }\end{array}$ & Structured survey & $\begin{array}{l}39.5 \% \text { trusted that COVID-19 vaccine would be safe and effective } \\
\text { Factors independently associated with trust included age } \\
(\mathrm{AOR}=1.03,95 \% \mathrm{CI}=1.02,1.05, p=0.0001) \text { and wearing a mask } \\
\text { all the time }(\mathrm{AOR}=2.48,95 \% \mathrm{CI}=1.86,3.31, p=0.0001) .\end{array}$ \\
\hline$[54]$ & & $\begin{array}{l}\text { ITQ; GAD-7; PHQ-9; vaccine } \\
\text { hesitancy ( } 8 \text { items); } 23 \text { items } \\
\quad \text { indexing severity of } \\
\text { COVID-19 vaccine side effect }\end{array}$ & $\begin{array}{c}\text { Participants with clinical PTSD levels showed more anxiety and } \\
\text { depressive symptoms, were vaccinated a few days later, showed } \\
\text { higher vaccine hesitancy levels, and displayed more severe } \\
\text { side effects. }\end{array}$ \\
\hline$[55]$ & $\begin{array}{l}\text { Cross } \\
\text { sectional study }\end{array}$ & $\begin{array}{l}\text { 21-item depression, anxiety } \\
\text { and stress scale }\end{array}$ & $\begin{array}{l}\text { A significantly higher proportion of people with depression or } \\
\text { anxiety disorder }(64.5 \%) \text { were more willing to pay for the } \\
\text { COVID-19 vaccine than healthy controls }(38.1 \%)(p \leq 0.001)\end{array}$ \\
\hline
\end{tabular}

Note: SMI = serious mental illness; ITQ = the international trauma questionnaire; GAD-7 = general anxiety disorder-7; PHQ-9 = patient health questionnaire-9; PTSD = post-traumatic stress disorder.

Four articles used assessment instruments: two research groups implemented structured surveys [52,53], the other two used standardized tests to investigate negative affect [55], vaccine hesitancy, and post-traumatic stress disorder (PTSD) symptoms [54]. Caution must be taken in interpreting these results based on a small sample [54,55] or survey-based design [30,37]. Having a full-blown psychiatric pathology seems to positively affect the attitude towards the vaccine $[53,55]$, and vaccine hesitancy does not appear to be a major barrier in this group [52], except for PTSD, associated with higher vaccine hesitancy and higher side effects [54]. "Wearing a mask all the time", age, and clinically significant anxious depressive symptoms was associated with higher trust in vaccine or willing to pay for it $[53,55]$.

\section{Conclusions and Future Directions}

From a speculative perspective, it is possible that the high values of declared adherence to the COVID-19 vaccine from people with mental disorders, compared with previous vaccination, may be secondary to a greater perception of risks and fear, thanks also to the high levels of general alarm that this pandemic has raised, differently from the previous ones. While functional fear might be related to increased compliance, especially in vulnerable groups [56], fear of the unknown has the potential to convert caution into paranoia and idiosyncratic beliefs in a large percentage of people [57,58]. The management of fear and anxiety should be a core focus of further investigations, implementing self-efficacy and a balanced view of risks. Further research should consider the difference between SMI and state symptomatology, especially when it concerns anxiety-depressive symptoms. Negative affect seems too generic a parameter for an accurate evaluation of the problem, different affect should be evaluated singularly. From another perspective, people with mental disorders might have insight of an implemented vulnerability towards any stressor compared with the general population. The ability of seeking support, which influences adherence during the emergence of acute symptoms, might also be a crucial personality trait for vaccine compliance.

Current evidence highlights that not all psychiatric patients are similar. The hyperarousal associated with PTSD might affect negatively the adherence of this groups of patients; specific interventions that take this into account should be envisaged to increase the efficacy of the vaccination campaign in this subgroup of patients. This study suggests that concerns about people with psychiatric conditions were based, in an early part of the pandemic, mainly on common sense and data on previous pandemics. The intense fear that accompanied the current world emergency has made this pandemic different from the previous ones, with changes of attitudes in the group of psychiatric patients. While 
psychological variables appear to be similar between general and psychiatric populations, they interact with specific psychopathological dimensions in the latter group. A deeper evaluation of vaccine hesitancy in patients with mental disorders should consider the differences between the distinct diagnostic categories, in order to be able to implement specific intervention measures tailored to the patient's pathology. It is also important to state that psychological characteristics of people who do not want to get the vaccine cannot be reduced to a psychiatric pathology but are probably more complex and require specific studies with standardized instruments. A comprehensive assessment of the personality, state and trait anxiety, and hyperarousal could be useful for better understanding differences between the general population and psychiatric patients.

Author Contributions: Conceptualization, S.G. and G.P. (Gianluca Pandolfo); methodology, G.P. (Gianluca Pandolfo); software, A.B.; validation, A.B., F.I. and G.P. (Giovanni Pioggia); formal analysis, G.P. (Gianluca Pandolfo); investigation, G.G.; resources, G.G.; data curation, F.I.; writing-original draft preparation, G.G.; writing-review and editing, G.P. (Gianluca Pandolfo); visualization, A.B.; supervision, S.G.; project administration, G.P. (Gianluca Pandolfo); funding acquisition, G.P. (Giovanni Pioggia). All authors have read and agreed to the published version of the manuscript.

Funding: This research received no external funding.

Institutional Review Board Statement: Not applicable.

Informed Consent Statement: Not applicable.

Data Availability Statement: https:/ / pubmed.ncbi.nlm.nih.gov / (accessed on 20 September 2021).

Conflicts of Interest: The authors declare no conflict of interest.

\section{References}

1. Aquino, F.; Donzelli, G.; De Franco, E.; Privitera, G.; Lopalco, P.L.; Carducci, A. The web and public confidence in MMR vaccination in Italy. Vaccine 2017, 35, 4494-4498. [CrossRef] [PubMed]

2. Sahin, U.; Karikó, K.; Türeci, Ö. mRNA-based therapeutics-Developing a new class of drugs. Nat. Rev. Drug Discov. 2014, 13, 759-780. [CrossRef]

3. Demyttenaere, K.; Bruffaerts, R.; Posada-Villa, J.; Gasquet, I.; Kovess, V.; Lepine, J.P.; Angermeyer, M.C.; Bernert, S.; de Girolamo, G.; Morosini, P.; et al. Prevalence, severity, and Unmet Need for Treatment of Mental Disorders in the World Health Organization World Mental Health Surveys. JAMA 2004, 291, 2581-2590. [PubMed]

4. Yamamoto, T.; Uchiumi, C.; Suzuki, N.; Yoshimoto, J.; Murillo-Rodriguez, E. The Psychological Impact of 'Mild Lockdown' in Japan during the COVID-19 Pandemic: A Nationwide Survey under a Declared State of Emergency. Int. J. Environ. Res. Public Health 2020, 17, 9382. [CrossRef] [PubMed]

5. World Health Organization. The Impact of COVID-19 on Mental, Neurological and Substance Use Services: Results of a Rapid Assessment; World Health Organization: Geneva, Switzerland, 2020.

6. Wang, Q.; Xu, R.; Volkow, N.D. Increased risk of COVID-19 infection and mortality in people with mental disorders: Analysis from electronic health records in the United States. World Psychiatry 2021, 20, 124-130. [CrossRef]

7. Li, L.; Li, F.; Fortunati, F.; Krystal, J.H. Association of a Prior Psychiatric Diagnosis with Mortality Among Hospitalized Patients with Coronavirus Disease 2019 (COVID-19) Infection. JAMA Netw. Open 2020, 3, e2023282. [CrossRef]

8. Nemani, K.; Li, C.; Olfson, M.; Blessing, E.M.; Razavian, N.; Chen, J.; Petkova, E.; Goff, D.C. Association of Psychiatric Disorders with Mortality Among Patients With COVID-19. JAMA Psychiatry 2021, 78, 380. [CrossRef]

9. Robillard, R.; Daros, A.R.; Phillips, J.L.; Porteous, M.; Saad, M.; Pennestri, M.-H.; Kendzerska, T.; Edwards, J.D.; Solomonova, E.; Bhatla, R.; et al. Emerging New Psychiatric Symptoms and the Worsening of Pre-existing Mental Disorders during the COVID-19 Pandemic: A Canadian Multisite Study: Nouveaux symptômes psychiatriques émergents et détérioration des troubles mentaux préexistants durant la pandémie de la COVID-19: Une étude canadienne multisite. Can. J. Psychiatry 2021, 66, 815-826. [CrossRef]

10. Hao, F.; Tan, W.; Jiang, L.; Zhang, L.; Zhao, X.; Zou, Y.; Hu, Y.; Luo, X.; Jiang, X.; McIntyre, R.S.; et al. Do psychiatric patients experience more psychiatric symptoms during COVID-19 pandemic and lockdown? A case-control study with service and research implications for immunopsychiatry. Brain Behav. Immun. 2020, 87, 100-106. [CrossRef]

11. Yao, H.; Chen, J.-H.; Xu, Y.-F. Patients with mental health disorders in the COVID-19 epidemic. Lancet Psychiatry 2020, 7, e21. [CrossRef]

12. Yard, E.; Radhakrishnan, L.; Ballesteros, M.F.; Sheppard, M.; Gates, A.; Stein, Z.; Hartnett, K.; Kite-Powell, A.; Rodgers, L.; Adjemian, J.; et al. Emergency Department Visits for Suspected Suicide Attempts Among Persons Aged 12-25 Years Before and During the COVID-19 Pandemic-United States, January 2019-May 2021. MMWR Morb. Mortal. Wkly. Rep. 2021, 70, 888-894. [CrossRef] 
13. Vahratian, A.; Blumberg, S.J.; Terlizzi, E.P.; Schiller, J.S. Symptoms of Anxiety or Depressive Disorder and Use of Mental Health Care Among Adults During the COVID-19 Pandemic-United States, August 2020-February 2021. MMWR Morb. Mortal. Wkly. Rep. 2021, 70, 490-494. [CrossRef]

14. McKnight-Eily, L.R.; Okoro, C.A.; Strine, T.W.; Verlenden, J.; Hollis, N.D.; Njai, R.; Mitchell, E.W.; Board, A.; Puddy, R.; Thomas, C. Racial and Ethnic Disparities in the Prevalence of Stress and Worry, Mental Health Conditions, and Increased Substance Use Among Adults During the COVID-19 Pandemic-United States, April and May 2020. MMWR Morb. Mortal. Wkly. Rep. 2021, 70, 162-166. [CrossRef]

15. Czeisler, M.É.; Lane, R.I.; Petrosky, E.; Wiley, J.F.; Christensen, A.; Njai, R.; Weaver, M.D.; Robbins, R.; Facer-Childs, E.R.; Barger L.K.; et al. Mental Health, Substance Use, and Suicidal Ideation During the COVID-19 Pandemic-United States, June 24-30, 2020. MMWR Morb. Mortal. Wkly. Rep. 2020, 69, 1049-1057. [CrossRef] [PubMed]

16. Vindegaard, N.; Benros, M.E. COVID-19 pandemic and mental health consequences: Systematic review of the current evidence. Brain Behav. Immun. 2020, 89, 531-542. [CrossRef] [PubMed]

17. Schou, T.M.; Joca, S.; Wegener, G.; Bay-Richter, C. Psychiatric and neuropsychiatric sequelae of COVID-19-A systematic review. Brain Behav. Immun. 2021, 97, 328-348. [CrossRef]

18. Bottemanne, H.; Delaigue, F.; Lemogne, C. SARS-CoV-2 Psychiatric Sequelae: An Urgent Need of Prevention. Front. Psychiatry 2021, 12, 738696. [CrossRef]

19. Mazereel, V.; Van Assche, K.; Detraux, J.; De Hert, M. COVID-19 vaccination for people with severe mental illness: Why, what, and how? Lancet Psychiatry 2021, 8, 444-450. [CrossRef]

20. Karafillakis, E.; Larson, H.J. The benefit of the doubt or doubts over benefits? A systematic literature review of perceived risks of vaccines in European populations. Vaccine 2017, 35, 4840-4850. [CrossRef]

21. Larson, H.J.; Clarke, R.M.; Jarrett, C.; Eckersberger, E.; Levine, Z.; Schulz, W.S.; Paterson, P. Measuring trust in vaccination: A systematic review. Hum. Vaccin. Immunother. 2018, 14, 1599-1609. [CrossRef]

22. MacDonald, N.E. Vaccine hesitancy: Definition, scope and determinants. Vaccine 2015, 33, 4161-4164. [CrossRef] [PubMed]

23. Bertoncello, C.; Ferro, A.; Fonzo, M.; Zanovello, S.; Napoletano, G.; Russo, F.; Baldo, V.; Cocchio, S. Socioeconomic Determinants in Vaccine Hesitancy and Vaccine Refusal in Italy. Vaccines 2020, 8, 276. [CrossRef]

24. Savas, E.; Tanriverdi, D. Knowledge, attitudes and anxiety towards influenza A/H1N1 vaccination of healthcare workers in Turkey. BMC Infect. Dis. 2010, 10, 281. [CrossRef] [PubMed]

25. Chan, E.Y.-Y.; Cheng, C.K.-Y.; Tam, G.C.-H.; Huang, Z.; Lee, P.Y. Willingness of future A/H7N9 influenza vaccine uptake: A cross-sectional study of Hong Kong community. Vaccine 2015, 33, 4737-4740. [CrossRef] [PubMed]

26. Mohammed, H.; Roberts, C.T.; Grzeskowiak, L.E.; Giles, L.; Leemaqz, S.; Dalton, J.; Dekker, G.; Marshall, H.S. Psychosocial determinants of pertussis and influenza vaccine uptake in pregnant women: A prospective study. Vaccine 2020, 38, 3358-3368 [CrossRef]

27. Lorenz, R.A.; Norris, M.M.; Norton, L.C.; Westrick, S.C. Factors Associated with Influenza Vaccination Decisions among Patients with Mental Illness. Int. J. Psychiatry Med. 2013, 46, 1-13. [CrossRef]

28. Schmid, P.; Rauber, D.; Betsch, C.; Lidolt, G.; Denker, M.-L. Barriers of Influenza Vaccination Intention and Behavior-A Systematic Review of Influenza Vaccine Hesitancy, 2005-2016. PLoS ONE 2017, 12, e0170550. [CrossRef]

29. Maguire, P.A.; Reay, R.E.; Looi, J.C. Nothing to sneeze at-Uptake of protective measures against an influenza pandemic by people with schizophrenia: Willingness and perceived barriers. Australas. Psychiatry 2019, 27, 171-178. [CrossRef]

30. Maguire, P.A.; Reay, R.E.; Looi, J.C. A sense of dread: Affect and risk perception in people with schizophrenia during an influenza pandemic. Australas. Psychiatry 2019, 27, 450-455. [CrossRef]

31. Lawrence, T.; Zubatsky, M.; Meyer, D. The association between mental health diagnoses and influenza vaccine receipt among older primary care patients. Psychol. Health Med. 2020, 25, 1083-1093. [CrossRef]

32. Lockett, H.; Koning, A.; Lacey, C.; Every-Palmer, S.; Scott, K.M.; Cunningham, R.; Dowell, T.; Smith, L.; Masters, A.; Culver, A.; et al. Addressing structural discrimination: Prioritising people with mental health and addiction issues during the COVID-19 pandemic. N. Z. Med. J. 2021, 134, 128-134.

33. Jakhar, J.; Naik, S.S.; Prasad, S. COVID-19 vaccination prioritization for persons with severe mental illness. Asian J. Psychiatry 2021, 64, 102792. [CrossRef] [PubMed]

34. The Lancet Psychiatry. A matter of priority: COVID-19 vaccination and mental health. Lancet Psychiatry 2021, 8, 551. [CrossRef]

35. Usher, K. Ensuring COVID-19 vaccine uptake by people with severe mental illness: A mental health nursing priority. Int. J. Ment. Health Nurs. 2021, 30, 819-820. [CrossRef] [PubMed]

36. Smith, K.; Lambe, S.; Freeman, D.; Cipriani, A. COVID-19 vaccines, hesitancy and mental health. Evid. Based Ment. Health 2021, 24, 47-48. [CrossRef] [PubMed]

37. Siva, N. Severe mental illness: Reassessing COVID-19 vaccine priorities. Lancet 2021, 397, 657. [CrossRef]

38. De Hert, M.; Mazereel, V.; Detraux, J.; Van Assche, K. Prioritizing COVID-19 vaccination for people with severe mental illness. World Psychiatry 2021, 20, 54-55. [CrossRef]

39. Barocas, J.A. Business Not as Usual-COVID-19 Vaccination in Persons with Substance Use Disorders. N. Engl. J. Med. 2021, 384, e6. [CrossRef]

40. Ahmadi, A.; Ntacyabukura, B.; Lucero-Prisno, D.E., III. Afghanistan: Vaccinate drug users against COVID-19. Nature 2021, 593, 195. [CrossRef] 
41. Hossain, M.K.; Hassanzadeganroudsari, M.; Apostolopoulos, V. Why METH users are at high risk of fatality due to COVID-19 infection? Expert Rev. Vaccines 2020, 19, 1101-1103. [CrossRef]

42. Trujols, J.; Cadafalch, J.; Alvarado, P.J.; Duran-Sindreu, S. Por una priorización de las personas con trastornos adictivos en la vacunación frente a la COVID-19. Adicciones 2021, 33, 285. [CrossRef]

43. Kumar, S.; Pathare, S.; Esponda, G.M. COVID-19 vaccine prioritisation for individuals with psychoses. Lancet Psychiatry 2021, 8, 751. [CrossRef]

44. The American Psychiatric Association (APA). COVID-19 Pandemic Guidance Document. The Role of the Psychiatrist in the Equitable Distribution of the COVID-19 Vaccine; The American Psychiatric Association: Washington, DC, USA, 2021.

45. Rehman, S.; Lela, U. Pharmacological treatment during COVID-19 and mental health issues. Riv. Psichiatr. 2021, 56, 53-55. [PubMed]

46. Yang, Y.; Li, W.; Zhang, Q.; Zhang, L.; Cheung, T.; Ng, C.H.; Xiang, Y.-T. Should people with severe mental illness be prioritized for the COVID-19 vaccination? Int. J. Biol. Sci. 2021, 17, 1443-1445. [CrossRef]

47. Toubasi, A.A.; AbuAnzeh, R.B.; Tawileh, H.B.A.; Aldebei, R.H.; Alryalat, S.A.S. A meta-analysis: The mortality and severity of COVID-19 among patients with mental disorders. Psychiatry Res. 2021, 299, 113856. [CrossRef] [PubMed]

48. Palermo, S. COVID-19 Pandemic: Maximizing Future Vaccination Treatments Considering Aging and Frailty. Front. Med. 2020, 7, 558835. [CrossRef]

49. Mascayano, F.; Bruni, A.; Susser, E. Implications of Global and Local Inequalities in COVID-19 Vaccine Distribution for People with Severe Mental Disorders in Latin America. JAMA Psychiatry 2021, 78, 945. [CrossRef] [PubMed]

50. Warren, N.; Kisely, S.; Siskind, D. Maximizing the Uptake of a COVID-19 Vaccine in People with Severe Mental Illness. JAMA Psychiatry 2021, 78, 589. [CrossRef]

51. Salles, C.; de Freitas, M.C.S.; Meira e Cruz, M. Comorbid insomnia and sleep apnea (COMISA) as an additional risk factor for reduced response to the COVID-19 vaccination? Sleep Med. 2021, 83, 159. [CrossRef]

52. Jefsen, O.H.; Kølbæk, P.; Gil, Y.; Speed, M.; Dinesen, P.T.; Sønderskov, K.M.; Østergaard, S.D. COVID-19 vaccine willingness amongst patients with mental illness compared with the general population. Acta Neuropsychiatr. 2021, 33, 273-276. [CrossRef]

53. Masson, C.L.; McCuistian, C.; Straus, E.; Elahi, S.; Chen, M.; Gruber, V.A.; Le, T.; Guydish, J. COVID-19 vaccine trust among clients in a sample of California residential substance use treatment programs. Drug Alcohol Depend. 2021, 225, 108812. [CrossRef] [PubMed]

54. Palgi, Y.; Greenblatt-Kimron, L.; Hoffman, Y.; Goodwin, R.; Ben-Ezra, M. Factors associated with current posttraumatic stress disorder among COVID-19 vaccinated older adults in Israel. J. Psychiatry Res. 2021, 142, 272-274. [CrossRef] [PubMed]

55. Hao, F.; Wang, B.; Tan, W.; Husain, S.F.; McIntyre, R.S.; Tang, X.; Zhang, L.; Han, X.; Jiang, L.; Chew, N.W.S.; et al. Attitudes toward COVID-19 vaccination and willingness to pay: Comparison of people with and without mental disorders in China. BJPsych Open 2021, 7, e146. [CrossRef]

56. Harper, C.A.; Satchell, L.P.; Fido, D.; Latzman, R.D. Functional Fear Predicts Public Health Compliance in the COVID-19 Pandemic. Int. J. Ment. Health Addict. 2021, 19, 1875-1888. [CrossRef]

57. Goldberg, J.F. How Should Psychiatry Respond to COVID-19 Anti-Vax Attitudes? J. Clin. Psychiatry 2021, 82, 21 ed14213. [CrossRef] [PubMed]

58. Freeman, D.; Waite, F.; Rosebrock, L.; Petit, A.; Causier, C.; East, A.; Jenner, L.; Teale, A.-L.; Carr, L.; Mulhall, S.; et al. Coronavirus conspiracy beliefs, mistrust, and compliance with government guidelines in England. Psychol. Med. 2022, 52, 251-263. [CrossRef] 